\title{
AGILE - SCRUM Method dalam Pengembangan Sistem Informasi Invetory Berbasis Website
}

\author{
Mukrodin \\ e-mail : mukrodins@gmail.com \\ Program Studi Sistem Informasi Fakultas Sains dan Teknologi Universitas Peradaban \\ J1. Raya Pagojengan Km.3 Paguyangan, Kec. Paguyangan, Kab. Brebes, telp. 0289-432032
}

\begin{abstract}
Abstrak
Dinas Penanaman Modal dan Pelayanan Terpadu Satu Pintu Kabupaten Banyumas merupakan Badan Usaha Milik Negara yang bergerak dalam bidang jasa, melayani berbagai jenis perizinan dan non perizinan. Masalah yang terjadi di Dinas Penanaman Modal dan Pelayanan Terpadu Satu Pintu Kabupaten Banyumas adalah dalam pengelolaan inventory barang. Dalam proses pendataan inventaris barang di gudang tersebut masih mengalami kendala, dengan sistem pencatatan yang manual menggunakan berbagai macam formulir, buku besar, dan proses input rekapitulasi data menggunakan software Spread sheet menyebabkan sulitnya mencari data-data yang di perlukan, kehilangan data karena tercecernya formulir, serta pegawai yang kurang memiliki kemampuan mengolah data dengan barbagai rumus dari aplikasi Spread sheet. Oleh sebab itu, perlu dilakukan pengembangan sistem inventory barang yang dapat mengatasi berbagai kendala dan permasalahan yang terjadi dengan memanfaatkan kemajuan teknologi yang ada, yaitu membangun aplikasi berbasis web yang dapat memberikan informasi yang dibutuhkan secara realtime dan akses data yang cepat, sehingga jika ada barang masuk serta ada perubahan pada status barang pegawai bisa langsung mengakses data tersebut. Dalam Perancangan sistem yang dilakukan dengan menggunakan penerapan agile method dengan model scrum yang merupakan pengembangan piranti lunak secara cepat di mana orang-orang dapat menyelesaikan permasalahan kompleks dan menghasilkan produk dengan nilai setinggi mungkin secara kreatif dan produktif.
\end{abstract}

Kata kunci : Metode Agile-scrum, Inventory, Website.

\section{Pendahuluan}

Informasi sudah menjadi kebutuhan untuk semua orang. Untuk itu, kriteria dalam informasi yaitu akurat, tepat, dan lengkap harus ada di dalamnya. Apabila kriteria tersebut sudah dipenuhi maka makna dalam informasi dapat diserap oleh setiap orang. Hal ini berlaku diberbagai aspek seperti dalam instansi swasta maupun instansi pemerintah. Penyajian informasi yang memenuhi kriteria diatas telah ada dalam salah satu instansi pemerintah yaitu Dinas Penanaman Modal dan Pelayanan Terpadu Satu Pintu (DPMPTSP) Kabupaten Banyumas. Dinas Penanaman Modal dan Pelayanan Terpadu Satu Pintu merupakan Badan Usaha Milik Negara yang bergerak dalam bidang jasa, melayani berbagai jenis perizinan, dan non perizinan, misalnya Izin Mendirikan Bangunan (IMB), izin mendirikan rumah sakit, dan masih banyak lagi perizinan lainnya. Dalam kinerjanya para pegawai pasti membutuhkan alat tulis kantor dan fasilitas yang menunjang kerja. Fasilitas tersebut harus mempermudah pegawai agar informasi yang diberikan lebih cepat dan tepat.

Pada Dinas tersebut terdapat berbagai sub bagian, diantaranya sub bagian umum dan kepegawaian. Dalam sub bagian kepegawaian menangani pembagian tugas kepada bawahan di lingkungan umum, sedangkan sub bagian umum menangani perencaaan kegiatan sub bagian umum dan kepegawaian berdasarkan rencana operasi sekretaris sebagai pedoman pelaksana tugas. Sub bagian umum memiliki tempat untuk menyimpan barang kebutuhan yang diperlukan oleh para pegawai dalam satu gudang. Selama ini dalam proses pendataan inventaris barang digudang tersebut masih mengalami kendala, dengan sistem pencatatan yang manual menggunakan berbagai macam formulir, buku besar, dan proses input rekapitulasi data menggunakan software Spread sheet menyebabkan sulitnya mencari data-data yang di perlukan, kehilangan data karena tercecernya formulir, serta pegawai yang kurang memiliki kemampuan mengolah data dengan barbagai rumus dari aplikasi Spread sheet. Oleh sebab itu, perlu dilakukan pengembangan sistem inventory barang yang dapat mengatasi berbagai kendala dan permasalahan yang terjadi dengan memanfaatkan kemajuan teknologi yang ada, yaitu membangun aplikasi berbasis web yang dapat memberikan informasi yang dibutuhkan 
secara realtime dan akses data yang cepat, sehingga jika ada barang masuk serta ada perubahan pada status barang pegawai bisa langsung mengakses data tersebut. Dalam membangun sebuah sistem inventory perlu adanya rancangan agar program tersebut dapat berjalan sesuai waktu yang telah ditentukan. Untuk pelaksanaannya diperlukan suatu metodologi. Dalam hal ini peneliti memilih salah satu metode yaitu agile-scrum. "Agile software development methods atau agile methodology merupakan sekumpulan metodologi pengembangan perangkat lunak yang berbasis pada pengembangan iteratif, di mana persyaratan dan solusi berkembang melalui kolaborasi antar tim yang terorganisir" [1]. Ada beberapa model pengembangan perangkat lunak yang termasuk agile software development methods, yaitu: Extrem Programming, Adaptive Software Development, Dynamic Systems, Model Scrum, Agile Modeling. Dalam penelitian ini model yang akan digunakan adalah model scrum.

"Model scrum adalah metode pengembangan piranti lunak secara cepat (agile). Prinsip scrum sesuai dengan prinsipprinsip yang terdapat pada metode pengembangan piranti secara cepat yang digunakan untuk menuntun kegiatan pengembangan piranti lunak, seperti pemenuhan kebutuhan, analisa, desain, dan penyampaian (delivery)"[1]. Peneliti menggunakan metode agile-scrum karena ada banyak keuntungan dalam mengimplementasikan metode agile-scrum dalam membangun sebuah sistem, di antaranya keterlibatan stakeholder, transparasi, pengiriman awal dan mudah diprediksi, biaya dan jadwal bisa di tentukan, memungkinkan perubahan, berfokus pada nilai bisnis serta meningkatkan kualitas [2].

Dengan metode tersebut peneliti membuat sistem informasi inventory barang dengan harapan dapat mengatasi kendala yang dihadapi para pegawai dalam proses persediaan barang. Dalam kegiatan ini peneliti mengembangkan sistem informasi untuk mengatasi kendala pada inventarisasi barang dengan judul "Agile - Scrum Method Dalam Pengembangan Sistem Informasi Invetory Berbasis Website".

\section{Metode Penelitian}

Metode pengembangan sistem yang digunakan dalam membangun sistem informasi inventory barang berbasis website pada Dinas Penanaman Modal dan Pelayanan Terpadu Satu Pintu Kabupaten Banyumas adalah dengan menggunakan metode agile-scrum. Metode scrum adalah sebuah kerangka kerja di mana orang-orang dapat menyelesaikan permasalahan kompleks yang senantiasa berubah, di mana pada saat bersamaan menghasilkan produk dengan nilai setinggi mungkin secara kreatif dan produktif [10].

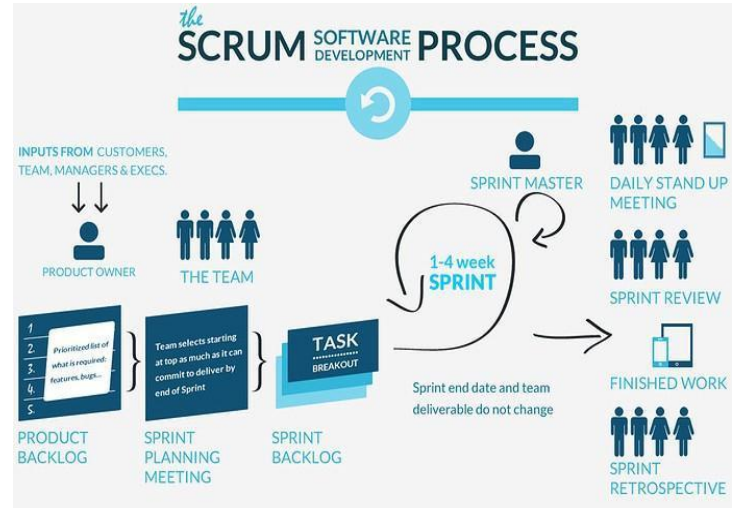

Gambar 1. Tahapan dan pihak yang terlibat dalam scrum

Acara ini dilakukan pada akhir sprint untuk meninjau dan merubah product backlog jika diperlukan. Tim scrum dan stakeholder akan berkolaborasi untuk membahas apa yang telah dikerjakan pada sprint yang baru selesai. Kemudian para hadirin berkolaborasi menentukan apa yang dapat dikerjakan di sprint berikutnya untuk mengoptimalkan nilai produk. Hasil dari sprint review adalah revisi dari product backlog yang mendefinisikan kemungkinan item product backlog untuk sprint berikutnya.

Metode blackbox testing adalah sebuah metode yang di pakai untuk menguji sebuah metode yang dipakai untuk menguji sebuah software tanpa harus memperhatikan detail software. Pengujian ini hanya memeriksa nilai keluaran berdasarkan nilai masukan masingmasing. Tidak ada upaya untuk mengetahui kode program apa yang output pakai [11]. Proses blackbox testing dengan cara mencoba memasukkan data pada setiap formnya. Pengujian ini diperlukan untuk mengetahui program tersebut berjalan sesuai dengan yang dibutuhkan oleh perusahaan [11]. Pengujian 
blackbox testing memiliki beberapa teknik diantaranya Equivalence Partitioning, Boundary Value Analysis, Robustness Testing, Behavior Testing dan Cause-Effect Relationship Testing [12].

\section{Hasil dan Pembahasan}

Perancangan aplikasi sistem inventory barang yang di bangun ini menggunakan Unified Modeling Language (UML) sebagai bahasa permodelan dan menggunakan metodologi agile-scrum sebagai kerangka kerjanya. Pembangunan sistem informasi inventory barang di Dinas Penanaman Modal dan Pelayanan Terpadu Satu Pintu Kabupaten Banyumas ini menggunakan tools utama sebagai berikut:

1. CodeIgniter sebagai framework untuk membaca bahasa pemprograman PHP.

2. MySQL sebagai database server.

3. PHPMyAdmin sebagai tools untuk mengelola database berbasis web.

Setelah melakukan pengenalan lingkungan kerja pada awal pelaksanaan praktek Kerja Lapangan, selanjutnya proses Praktek Kerja Lapangan dapat di bagi menjadi beberapa tahap, yaitu Pengamatan \& analisis kebutuhan sistem. Pengamatan dilakukan dengan mengamati bisnis proses sistem yang sudah berjalan, melalui diskusi dan wawancara dengan pengguna sistem. Setelah itu melakukan analisis kebutuhan sistem baik kebutuhan fungsional maupun non fungsional. Pemodelan sistem dengan menggunakan unified modeling language (UML) yaitu dengan menggunakan diagram use case, diagram activity, class diagram, dan Sequence diagram.

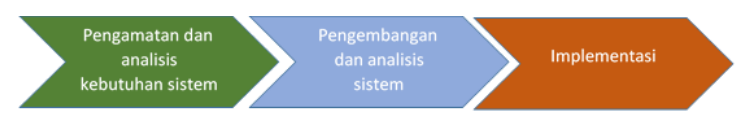

Gambar 2. Alur Penelitian

Metode pengembangan sistem mengacu pada metode scrum yang merupakan sebuah metode yang mudah di kontrol, fleksibel, memuat strategi pengembangan menyeluruh dimana seluruh tim bekerja sebagai satu unit untuk mencapai goal yang sama. Dalam pelaksanaannya metode ini memiliki beberapa tahapan scrum diantaranya : product backlog, sprint planning, daily stand up meeting, sprint review, sprint retrospective, increment.
Use case diagram dari website inventory barang pada Dinas Penanaman Modal Dan Pelayanan Terpadu Satu Pintu Kabupaten Banyumas adalah sebagai berikut :

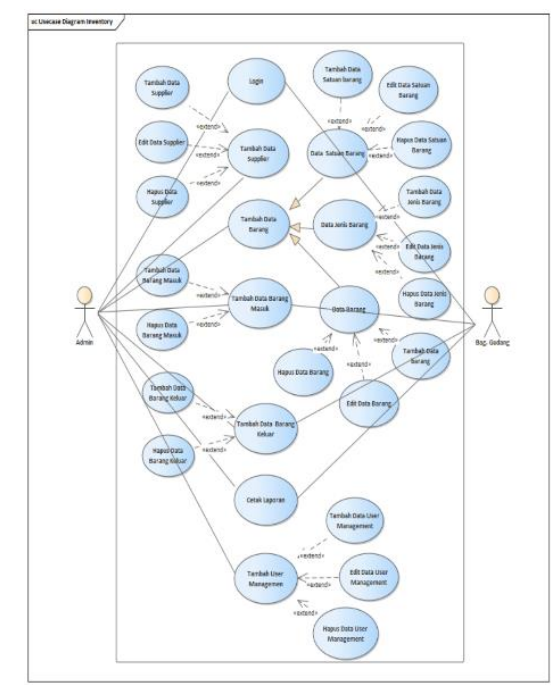

Gambar 3. Use Case Diagram Website Inventory

Class diagram adalah diagram yang digunakan untuk menampilkan beberapa kelas yang ada dalam sistem perangkat lunak yang akan dikembangkan. Class diagram menunjukkan hubungan antar class dalam sistem yang sedang dibangun dan bagaimana mereka saling berkolaborasi untuk mencapai tujuan. Berikut ini digambarkan class diagram dari website inventory barang pada Dinas Penanaman Modal Dan Pelayalanan Terpadu Satu Pintu Kabupaten Banyumas.

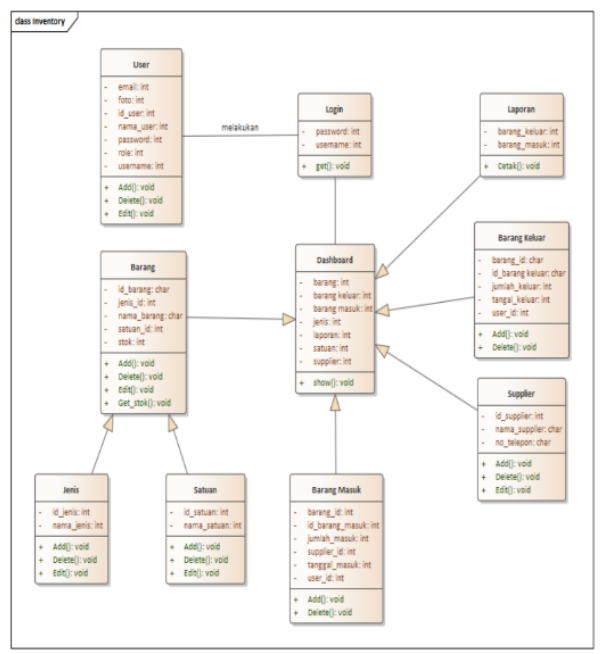

Gambar 4. Class Diagram Inventory 
Tahapan dalam penerapan metode scrum pada pengembangan sistem informasi inventory barang mencakup seluruh kebutuhan sistem informasi inventory barang dengan kebutuhan yang sudah di rancang sebelumnya.

\section{Menentukan Product Backlog}

Pada tahap ini, ditentukan semua kebutuhan pengguna baik yang bersifat fungsional maupun non fungsional beserta skala prioritasnya. Tahapan product backlog ini dibagi menjadi dua kategori pengguna sistem, yaitu admin dan bagian gudang. Setiap fitur backlog memiliki prioritas, hal ini ditentukan berdasarkan tingkat urgent dari kebutuhan pengguna. Prioritas menentukan fitur mana yang harus dikerjakan terlebih dahulu. Berikut ini merupakan daftar fitur yang akan dikembangkan dalam menentukan product backlog.

Tabel 1. Product Backlog

\begin{tabular}{cccc}
\hline No & $\begin{array}{c}\text { Deskripsi } \\
\text { Fitur }\end{array}$ & Prioritas & $\begin{array}{c}\text { Estimasi } \\
\text { Waktu } \\
(\text { Jam })\end{array}$ \\
\hline 1 & Login & Tinggi & 40 \\
2 & Dashoard & Tinggi & 32 \\
3 & Data Master & Sangat tinggi & 56 \\
4 & Transaksi & Sangat tinggi & 56 \\
5 & Report & Sangat tinggi & 56 \\
6 & Setting & Sangat tinggi & 56
\end{tabular}

\section{Menentukan Sprint}

Pada tahap ini ditentukan sprint dari product backlog. Sprint yang dihasilkan berjumlah 6 sprint dengan pertimbangan fitur backlog, task dan estimasi waktu (jam) sesuai ketentuan dalam scrum. Product backlog yang akan dikerjakan pada sprint 1 fokus pada kebutuhan aplikasi dari sisi kategori fitur login. Product backlog yang di kerjakan, antara lain :
Tabel 2. Sprint : Pengelolaan Fitur

Login

\begin{tabular}{lccc}
\hline $\begin{array}{c}\text { Fitur } \\
\text { Backlog }\end{array}$ & Task & Estimasi Waktu \\
& & & \\
(Jam)
\end{tabular}

\section{Daily Stand Up Meeting}

Setelah menyelesaikan product backlog dan stand up planning meeting, aktivitas selanjutnya adalah daily stand up meeting. Aktivitas ini dilakukan untuk mengevaluasi tugas pekerjaan tim dari jam 09.00 sampai 09.15 setiap hari selama sprint berlangsung. Agenda harian ini dilakukan dalam rangka evaluasi tugas dan pekerjaan individu tim yang telah diselesaikan, kendala yang di hadapi serta solusi dan target penyelesaian sebagai bahan untuk pertemuan berikutnya.

\section{Sprint Review}

Tahapan yang ke 4 adalah sprint review setiap anggota tim mendemontrasikan tugas yang sudah di selesaikan dalam periode satu sprint. Demo pekerjaan yang sudah selesai dilaksanakan untuk memberikan informasi kepada pengguna dari perangkat lunak yang telah dihasilkan dan meminta masukan pendapat dari pengguna untuk dievaluasi.

\section{Sprint Retrospective}

Tahapan selanjutnya dari penerapan scrum adalah sprint retrospective yang di lakukan pada setiap sprint yang berakhir. Pada tahapan ini semua anggota tim dapat menyampaikan pendapat dan evaluasinya mengenai kinerja selama menerapkan metode scrum. 
Hasil pengembangan sistem dengan metode scrum di terapkan pada pengembangan sistem informasi inventory barang di Dinas Penanaman Modal Dan Pelayanan Terpadu Satu Pintu Kabupaten Banyumas. Berikut tampilan dari fitur dan menu website dari hasil pembangunan sistem inventory barang di Dinas Penanaman Modal Dan Pelayanan Terpadu Satu Pintu Kabupaten Banyumas :

1. Tampilan Form Login

Tampilan form login merupakan awal pada sistem inventory saat pertama kali di akses. Staff admin dan bagian gudang harus memasukkan username dan password

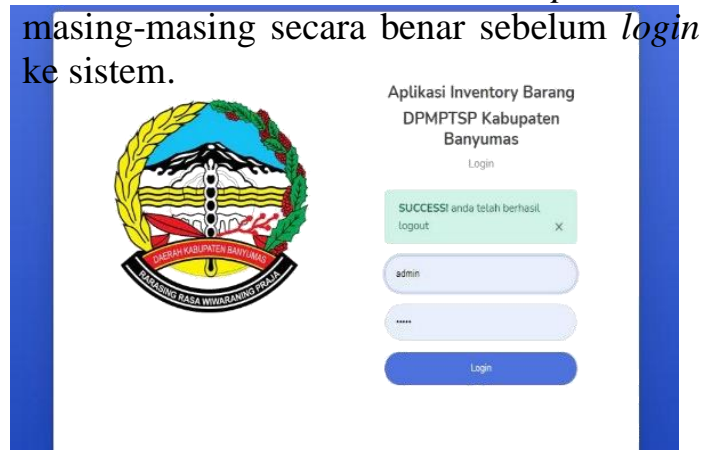

Gambar 4. Tampilan Form login

2. Tampilan Menu Dashboard

Pada menu utama berisi beberapa menu untuk mengakses fitur-fitur yang tersedia untuk admin dan Bagian gudang.

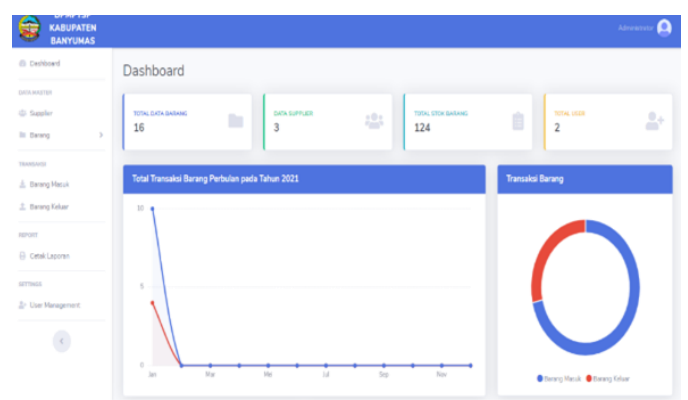

Gambar 5. Tampilan Menu Dashboard

\section{Kesimpulan}

Penelitian ini menghasilkan beberapa

kesimpulan antara lain:

1. Bagaimana menerapkan meteode AgileScrum dalam pengembangan sistem inventory barang dengan baik sesuai dengan kebutuhan.
2. Memberikan laporan pengadaan barang dengan cepat, tepat serta bisa dilakukan dimanapun dan kapapun karena berbasis website.

3. Melakukan pencegahan dari masalah kekurangan stok barang atau ketersediaan barang.

4. Mampu mengambil keputusan dengan cepat dan akurat.

\section{Daftar Pustaka}

[1] I. Mahendra and D. T. Eby Yanto, "Sistem Informasi Pengajuan Kredit

[2] Berbasis Web Menggunakan Agile Development Methods Pada Bank Bri Unit

[3] Kolonel Sugiono," J. Teknol. Dan Open Source, vol. 1, no. 2, pp. 13-24, 2018, doi: 10.36378/jtos.v1i2.20.

[4] M. N. Novri Hadinata, "Implementasi Metode Scrum Dalam Rancang Bangun Sistem Informasi Penjualan (Study Kasus : Penjualan Sperpart Kendaraan ),"

[5] J. Ilm. Betrik, vol. 08, no. 01, pp. 22-27, 2017, [Online]. Available: https://ejournal.lppmstipagaralam.ac.id/i ndex.php/betrik/index.

[6] Yakub, "Pengantar Sistem Informasi," Igarss 2014, 2014, doi: 10.1007/s13398014-0173-7.2.

[7] M. N. fahrisal, Sentosa Pohan, "Perancangan Sistem Inventory Barang Pada UD. Minang Dewi Berbasis Website,” Inform. J. Ilm. AMIK Labuhan Batu, vol. 6, pp. 17-19, 2018.

[8] A. Pattianakotta, A. A. E. Sinsuw, and A. S. M. L. St, "Sistem Informasi Arsip Dokumen Kantor Pelayanan Kekayaan Negara Dan Lelang Manado," J. Tek. Elektro dan Komput., vol. 4, no. 7, pp. 814, 2015.

[9] kasiman Peranginain, "aplikasi web dengan php dan mysql," informatika, 2006.

[10] Y. Syafitri, "Analisa Dan Perancangan Berbasis Uml Pada Sistem Informasi Simpan Pinjam Koperasi Swamitra Bandar Lampung,” J. Inf. dan Komput., 2016.

[11] Munawar, Analisis Perancangan Sistem Berbasis Objek dengan UML. 2018. 